\title{
Análise térmica do processo de soldagem TIG em um duto em operação através do método numérico de volumes finitos
}

\author{
Theo Martins de A. Paiva ${ }^{[1]}$, Jakson Gomes de O. Júnior ${ }^{[2]}$ e Francisco Edson N. Fraga ${ }^{[3]}$ \\ [1] Universidade Federal Rural do Semi-árido; theo_martins_alencar@ hotmail.com \\ [2] Universidade Federal Rural do Semi-árido; jakson117@ @ive.com \\ ${ }^{[3]}$ Universidade Federal Rural do Semi-árido; nfraga@ufersa.edu.br
}

Recebido: 25/06/2019;

Aceito: 25/08/2019;

Publicado: 07/10/2019.

Resumo: Este trabalho tem como objetivo a realização da modelagem e simulações do processo de soldagem TIG de um duto em operação, através do método numérico de volumes finitos, para a determinação dos ciclos térmicos e campos transientes de temperaturas ao qual o material está sujeito. Para tanto, foi utilizado o software Ansys Fluent $19.0^{\circledR}$, onde foi simulado o processo de soldagem TIG autógeno em um duto de aço AISI 1020, com água escoando em seu interior. $\mathrm{O}$ estudo do comportamento do material durante a soldagem em operação é de fundamental importância para a determinação de parâmetros de soldagens que possam ser aplicados no processo a fim de garantir a segurança da operação. Após a simulação do processo de soldagem em operação, foi possível determinar os ciclos térmicos a que está sujeito o duto, seus campos transientes de temperatura e o comportamento do fluido em seu interior, que chega a mudar de fase quando a fonte de calor está sobre a região, com tais dados, foi possível mensurar o resfriamento forçado a que a parede do duto está sujeita, parâmetros da solda, como a zona afetada pelo calor, a zona fundida e a penetração.

Palavras-chave: Soldagem em operação; soldagem TIG; simulação numérica computacional; volumes finitos

\section{INTRODUÇÃO}

$\mathrm{O}$ processo de soldagem de duto em operação, ou soldagem em carga, consiste em realizar reparos nas paredes de uma tubulação que apresente algum defeito, como a redução da espessura da parede devido a corrosão, sem que seja necessário interromper o funcionamento do sistema ao qual o duto pertence [1]. Este tipo de intervenção de manutenção apresenta não só vantagens técnicas como fazer um reparo mais pontual e assim evitando a troca de uma porção de tubulação, mas também vantagens econômicas, pois evita a interrupção da operação para a realização do reparo, não gerando perdas devido a paralização do processo.

Porém, a realização de tal procedimento pode apresentar alguns riscos, pois uma má avaliação da extensão do defeito a que se propõe a reparar pode fazer com que a realização da soldagem acarrete em acidentes, pois durante o processo da solda a parede da tubulação pode romper, causando o vazamento do fluido e o comprometimento do sistema como um todo, além do risco ao operador. A avaliação dos defeitos nas paredes de dutos deve obedecer determinadas normas para que seja conhecida a extensão do dano à tubulação, como exposto em [1], e se possa realizar o reparo de soldagem de dutos em operação com segurança.

Segundo relatório técnico da Petrobrás, citado por [1], existem três principais riscos que devem ser considerados para a realização da soldagem em carga, são eles:

- Risco de trincas devido a absorção de hidrogênio durante o processo de solda;

- Risco de o arco elétrico da solda penetrar o material;

- Risco de decomposição instável do produto devido à alta temperatura que a solda pode gerar no interior do duto. 
A realização de estudos a fim de analisar a ocorrência desses três riscos parte, geralmente, de uma análise térmica do processo de soldagem, afim de determinar os ciclos térmicos que o material irá sofrer e os campos transientes de temperatura, para a partir disso, determinar como será o comportamento do material que está sendo soldado durante o procedimento [2].

A análise térmica de um processo de soldagem pode ser feita através de métodos analíticos, que simplificam o processo ao desconsiderar as variações das propriedades físicas do material que dependem da temperatura, ou por meio de métodos numéricos, que mesmo apresentando simplificações, podem simular a variação de fatores termofísicos do material e a ocorrência de fenômenos como a convecção e a radiação, que influenciam na quantidade de calor transferida para a peça durante a soldagem.

A soldagem é um fenômeno altamente transiente [3], onde as variáveis termofísicas, como a condutividade e o calor específico, variam devido a temperatura e a quantidade de calor transferido para a peça, logo, simulações numéricas que levem essas mudanças em consideração são cada vez mais utilizadas para a análise térmica do processo de soldagem [4].

Com base no que foi exposto, o presente trabalho tem como objetivo a análise dos ciclos térmicos e campos transientes de temperatura de um duto em operação que sofre o processo de soldagem em carga. Para tanto, será feita uma análise numérica utilizando o Método de Volumes Finitos (MVF) levando em consideração a variação de parâmetros termofísicos do material soldado. A simulação da soldagem de duto em operação será realizada em uma tubulação com uma polegada de diâmetro e 3,2 mm de espessura de parede, com água escoando em seu interior. O processo será simulado no software ANSYS Fluent 19.0®. Para a representação da distribuição de energia da solda na simulação, foi escolhida a fonte de calor analítica volumétrica hemisférica (Gaussiana).

\section{FUNDAMENTAÇÃO TEÓRICA}

\subsection{Soldagem em operação}

Algumas das vantagens que o processo de soldagem em operação, ou soldagem em carga, apresenta, além da vantagem de não reduzir a produtividade durante a realização do reparo, são a economia de material, pois não será necessário trocar toda uma seção de dutos, e evitar que parte do fluido presente na tubulação escoe para o meio ambiente, o que geralmente ocorre na substituição de dutos [4].

Além da função em manutenção de dutos, a soldagem de tubulações em operação também é fundamental para o procedimento de trepanação (hot tapping), que consiste na instalação de conexões extras em uma linha principal de tubulações. O processo de soldagem em operação é cada vez mais necessário no território nacional, que conta com mais de $15.000 \mathrm{~km}$ de dutos terrestres, devido ao fato de que a instalação de grande parte dessas plantas de dutos terem sido feitas há mais de trinta anos, e a realização de reparos é cada vez maior [4].

A realização desse tipo de operação necessita da análise de alguns riscos inerentes ao processo para garantir a segurança, os principais, segundo relatório técnico da Petrobrás, citado por [1], são os riscos de trincas por hidrogênio, risco de perfuração do duto e o risco do superaquecimento do fluido que escoa.

Devido a esses riscos, a soldagem TIG se apresenta como a melhor opção para a realização desse procedimento, pois segundo [3, 6], possui um arco mais estável, o que permite um maior controle do aporte térmico e contribui para a prevenção da perfuração e do superaquecimento do fluido, além disso, possui o menor teor de hidrogênio difusível no metal de solda dentre os processos de soldagem mais utilizados na indústria [6], conforme mostra a Figura 1, o que previne a formação de trincas por hidrogênio no material. 


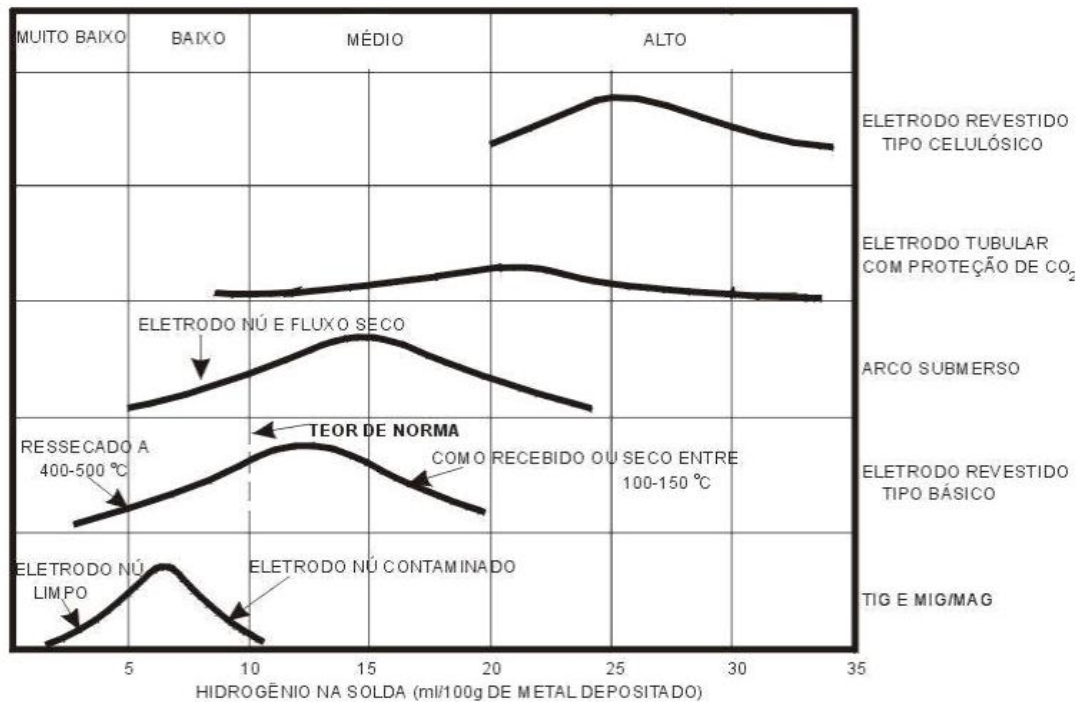

FiguRA 1. Teores típicos de hidrogênio difusível no metal de solda, em diversos processos. [4]

\subsection{Análise térmica}

Durante o processo de soldagem a arco, o calor é transferido da fonte elétrica da tocha para o material, essa energia térmica em trânsito é distribuída pelo material através de um fenômeno conhecido como condução. Porém, o calor não é somente transferido para a peça, ele também é perdido para o meio através da convecção e radiação [7].

O campo de temperaturas durante o processo de soldagem é governado pela equação de condução de calor, representada na Equação 1[7]:

$$
\rho(T) c(T) \frac{\partial T}{\partial t}(X, Y, Z, t)=-\nabla \vec{q}(X, Y, Z, t)+Q(X, Y, Z, t)
$$

onde, " $\rho$ " é a densidade do material $(\mathrm{kg} / \mathrm{m} 3)$, "c" o calor específico (J/kg.K), "t" é o tempo (s), "T" é a temperatura (K), "X, Y e Z" são as coordenadas do sistema de referência, " $\nabla \vec{q}$ ” indica o gradiente do vetor fluxo de calor e "Q" é a taxa de geração de calor por unidade de volume (W/m3).

Através da lei de Fourier, Equação 2, o vetor fluxo de calor da Equação 1, pode ser escrito da seguinte forma:

$$
\overrightarrow{\mathrm{q}}=-\mathrm{k}(\mathrm{T}) \nabla \mathrm{T}
$$

onde " $\mathrm{k}$ " é a condutividade térmica $(\mathrm{W} / \mathrm{m} . \mathrm{K})$ e " $\nabla T$ " é o gradiente térmico $(\mathrm{K} / \mathrm{m} 1)$, reescrevendo a Equação 1 substituindo esse termo, é obtida a Equação 3:

$$
\rho(T) c(T) \frac{\partial T}{\partial t}=\frac{\partial}{\partial X}\left(k_{X} \frac{\partial T}{\partial X}\right) \frac{\partial}{\partial Y}\left(k_{Y} \frac{\partial T}{\partial Y}\right) \frac{\partial}{\partial Z}\left(k_{Z} \frac{\partial T}{\partial Z}\right)+Q
$$

em que " $\mathrm{kX}, \mathrm{kY}$ e kZ" são os coeficientes de condutividade térmica nas direções $\mathrm{X}, \mathrm{Y}$ e Z, respectivamente.

As perdas de calor devido a convecção e a radiação podem ser definidas pelas Equações 4 e 5, respectivamente.

$$
\begin{aligned}
& \mathrm{q}_{\text {conv }}=\mathrm{h}\left(\mathrm{T}_{\mathrm{s}}-\mathrm{T}_{\infty}\right) \\
& \mathrm{q}_{\mathrm{rad}}=\varepsilon \sigma\left(\mathrm{T}_{\mathrm{s}}{ }^{4}-\mathrm{T}_{\mathrm{viz}}{ }^{4}\right)
\end{aligned}
$$

Para a Equação 4, " $q_{\text {conv }}$ " é a quantidade de calor transferida para o meio através da convecção, o coeficiente de convecção é representado pelo " $\mathrm{h}$ " (W/m2.K), " $T_{s}$ " e " $T_{\infty}$ " são as temperaturas da superfície e do fluido na vizinhança $(\mathrm{K})$, respectivamente. Já para a Equação 5, “ $q_{\text {rad }}$ ” representa a perca de calor para o meio devido a radiação, " $\varepsilon$ " representa a emissividade, variando entre 1 e 0 , a constante de Stefan-Boltzmann representada 
por “ $\sigma$ ” possui um valor de $5,67 \times 10^{-8}\left(\mathrm{~W} \cdot \mathrm{m}^{2} \cdot \mathrm{K}^{-4}\right)$, “TS” e “Tviz" são as temperaturas da superfície e da vizinhança $(\mathrm{K})$, respectivamente.

\subsection{Fontes analíticas de calor}

As fontes analíticas de calor são funções matemáticas que representam aproximações para a distribuição de temperatura em uma peça submetida a soldagem [8]. Para a obtenção de simulações confiáveis das condições térmicas que o processo de solda impõe sobre uma peça, a escolha de um modelo de fonte analítica de calor apropriada é de fundamental importância [7].

As fontes de calor se dividem em fontes pontuais, superficiais e volumétricas. Para processos de soldagem com penetrações mais altas no material e com grande quantidade de energia térmica transferida, as fontes de calor volumétricas são mais precisas, pois as fontes pontuais não adaptam muito bem um processo de soldagem com cordão de solda e as superficiais não representam bem a penetração da poça de fusão [6].

\subsubsection{Fonte de calor volumétrica - Hemisférica (Gaussiana)}

A fonte de calor analítica volumétrica hemisférica representa a distribuição de energia sobre a forma de uma curva gaussiana e a distribuição do calor na peça com o formato de um hemisfério de diâmetro DH [6], conforme mostra a Figura 2. Essa fonte analítica de calor é descrita através da Equação 6.

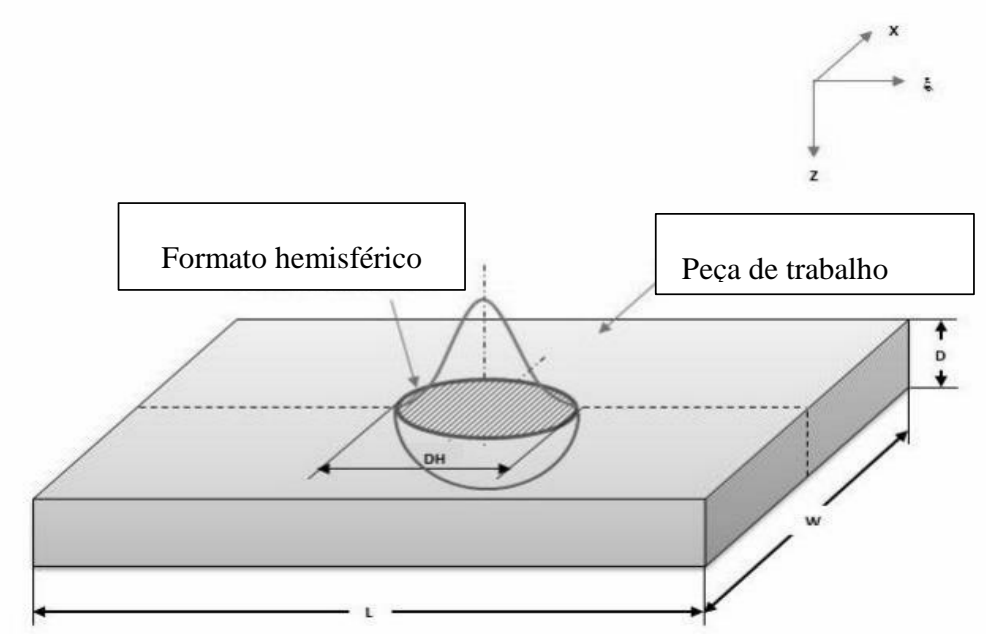

FIGURA 2. Distribuição de energia da fonte hemisférica. (Adaptado de 8)

$$
\mathrm{q}(\mathrm{x}, \mathrm{y}, \xi)=\frac{6 \sqrt{3} \mathrm{Q}}{\mathrm{c}^{3} \pi \sqrt{\pi}} \mathrm{e}^{-3 \mathrm{x}^{2} / \mathrm{c}^{2}} \mathrm{e}^{-3 \mathrm{y}^{2} / \mathrm{c}^{2}} \mathrm{e}^{-3 \xi^{2} / \mathrm{c}^{2}}
$$

Onde, "Q" representa a taxa de entrada de energia (W), o termo "c" é o raio característico da distribuição do fluxo de calor (m), "v" é a velocidade de soldagem usada no processo (m/s), "t" indica o tempo (s) e " $\xi$ " é a coordenada $\mathrm{Z}$ da fonte de calor ao longo do tempo tal que $\xi=\mathrm{z}+$ (v.t).

A taxa de entrada de energia Q, para um processo de soldagem, é definida através da Equação 7.

$$
\mathrm{Q}=\eta \mathrm{IV}
$$

Em que " $\eta$ " é a eficiência do processo de soldagem, em porcentagem, I é a corrente utilizada no processo de soldagem (A) e V é a tensão utilizada (V).

\subsection{Fluidodinâmica computacional (CFD)}

Na simulação do processo de soldagem de duto em operação, o efeito que o fluido irá exercer sobre os ciclos térmicos que o material da tubulação irá sofrer é de extrema relevância, pois causará um resfriamento acelerado do material soldado. Logo, o comportamento desse fluido deve ser levado em consideração na simulação do processo. 
As condições de escoamento do fluido são de extrema importância para determinar a retirada de calor da peça que ele ocasiona, pois, a mistura turbulenta do fluido ocasiona grandes gradientes de temperatura e transferência de calor, pois influencia na camada-limite térmica, que é compreendida como a região adjacente às paredes do duto e sofre, com mais intensidade, os efeitos dessa interface [9]. A simulação do regime turbulento do escoamento nas simulações em CFD é feita através da determinação de um modelo de turbulência.

\subsubsection{O modelo de turbulência $\kappa-\varepsilon$}

Desenvolvido por Brian Edward Launder e Dudley Brian Spalding em 1972, o $\kappa-\varepsilon$ é um modelo de turbulência, de duas equações, bastante utilizado para aplicações de engenharia e possui precisão considerável para a maioria das aplicações industriais [10]. Por ser um modelo de duas equações, ainda promove uma economia de recursos computacionais, pois diminui a quantidade de operações que a máquina realizará, reduzindo assim o tempo de simulação.

\section{MATERIAIS E MÉTODOS}

A simulação do processo de soldagem em operação foi realizada no software ANSYS Fluent 19.0®. Para a sua realização, primeiramente foram definidas as dimensões do modelo, para logo após a geração da malha e a modelagem da fonte de calor. Ainda foi necessária a definição das propriedades termofísicas do material e as condições de contorno da simulação. Todo esse processo está demonstrado na sequência lógica apresentada na Figura 3, após o término das simulações os resultados foram obtidos através do plugin CFD post processor do ANSYS®:

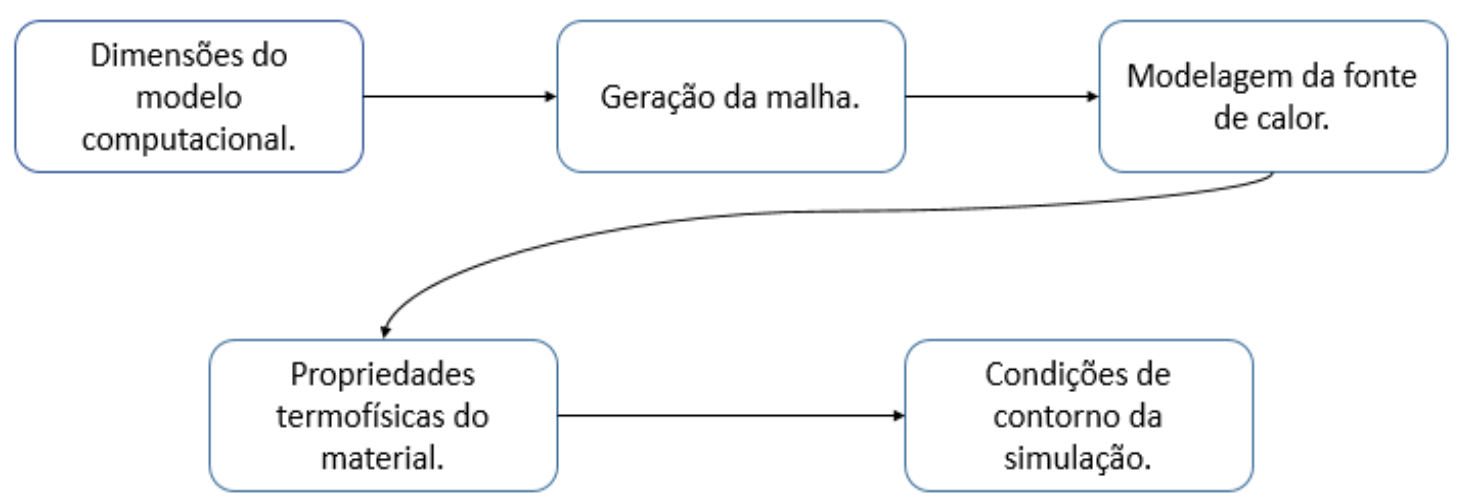

FIGURA 3. Fluxograma da simulação. (Autoria própria)

\subsection{Dimensões do modelo computacional}

Para a simulação, o modelo utilizado nesse trabalho foi um duto de 1" de diâmetro $(25,4 \mathrm{~mm}), 3,2 \mathrm{~mm}$ de espessura de parede e um comprimento de $200 \mathrm{~mm}$, a criação da peça foi feita através dos softwares SolidWorks 2015 e Design Modeler. O modelo consiste em três corpos, um constituído por um segmento de arco no qual será inserida a fonte de calor, o segundo com o restante do duto e um terceiro corpo que representa o fluido no interior da tubulação. O duto utilizado na simulação é mostrado na Figura 4. 


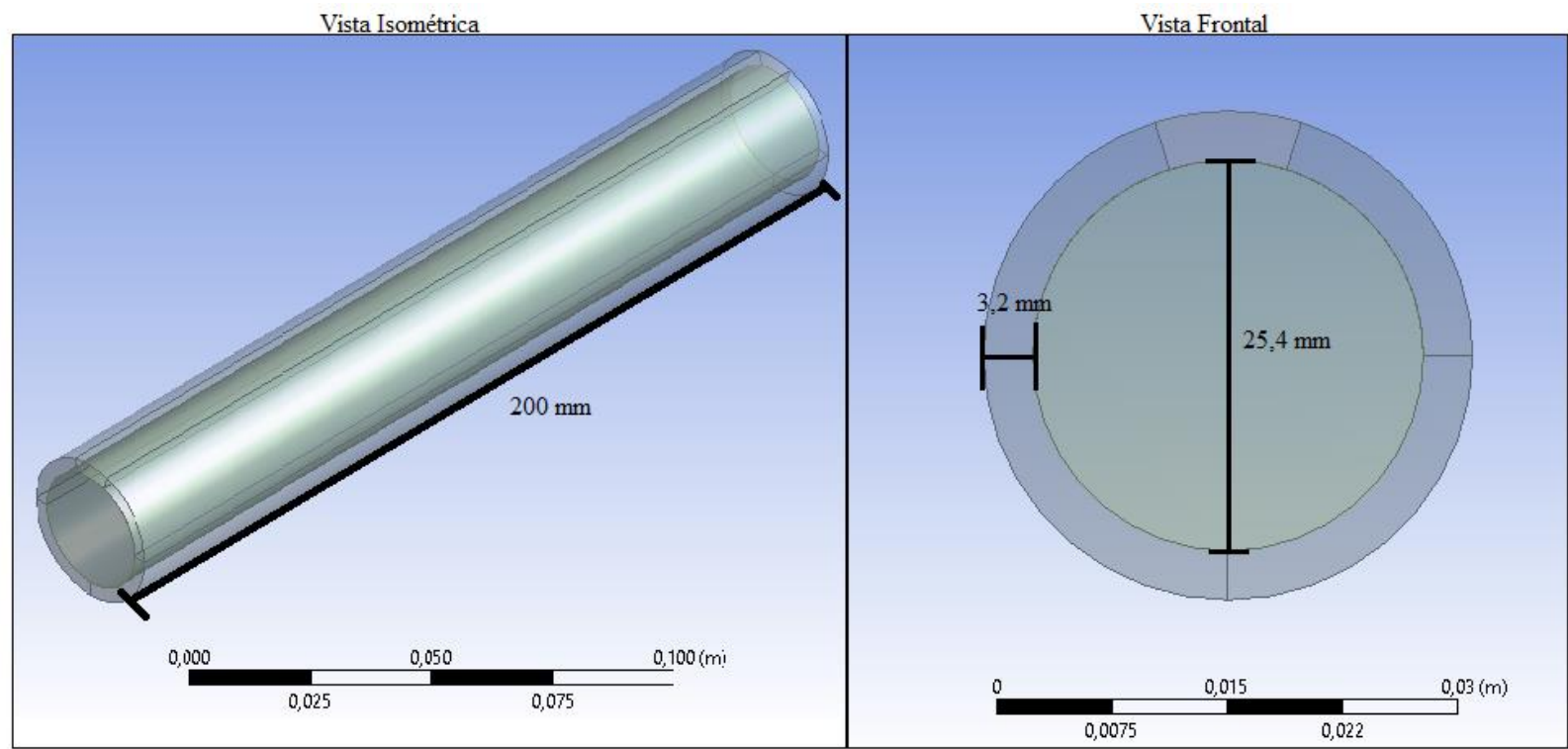

FIGURA 4. Modelo computacional utilizado. (Autoria própria)

\subsection{Geração da malha}

A geração da malha para a simulação foi dividida em duas etapas, a primeira consiste na criação de parte da malha na tubulação, e a segunda no fluido. Por simularem efeitos diferentes, a malha no duto a condução do calor e a no fluido o escoamento e a transferência de calor convectiva, as duas partes da malha foram geradas utilizando métricas diferentes, porém ambas são não estruturadas, devido a facilidade de construção em comparação com uma estruturada. Na geração das duas regiões da malha, foi realizado o refino nas regiões de maior interesse, como a região adjacente à parede do tubo onde ocorrem os efeitos viscosos mais intensos e a região onde a fonte de calor atua diretamente e consequentemente há uma maior troca de energia. A malha utilizada na simulação é apresentada na Figura 5.

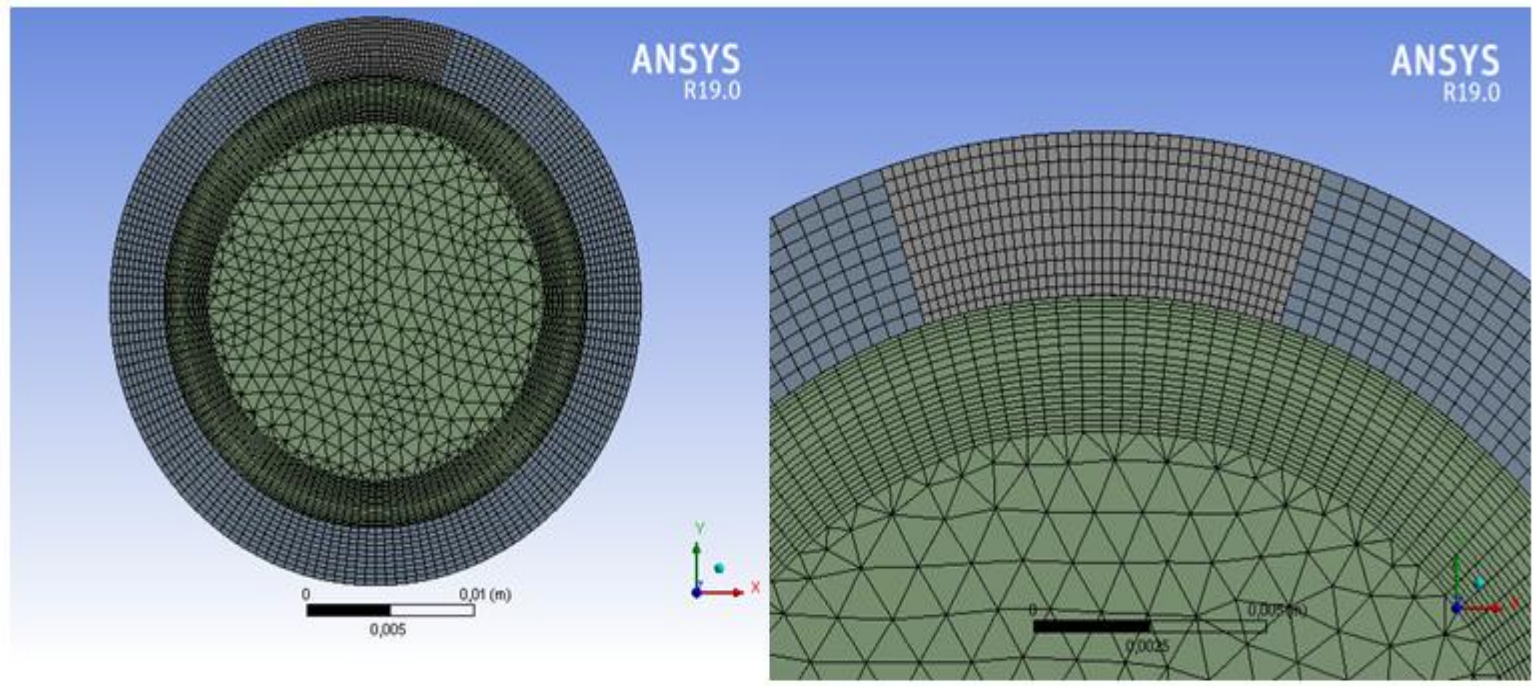

FIGURA 5. Malha utilizada na simulação. (Autoria própria)

\subsubsection{Geração da malha para o duto}

Para o duto foi utilizada uma malha formada, predominantemente, por elementos com geometria hexaédrica, o que permite uma economia computacional, pois requer um número menor de elementos quando comparado com o uso de geometria tetraédrica. Um maior refino da malha foi feito nas zonas próximas à zona fundida, devido ao maior aporte térmico nessa região e a alguns pontos de interesse se encontrarem nelas. 
Para garantir a convergência da malha, foi utilizado o parâmetro hi, apresentado por [11], que pode ser calculado através da Equação 8.

$$
\mathrm{h}_{\mathrm{i}}=\sqrt[3]{\frac{\mathrm{vol}}{\mathrm{N}}}
$$

onde vol representa o volume do domínio, $\mathrm{N}$ o número de nós em cada malha analisada. Foram geradas cinco malhas, seus valores de número de nós e relação $h_{i} / h_{1}$, onde $h_{1}$ é o menor valor de $h_{i}$, estão apresentados na Tabela 1:

TABELA 1. Parâmetro $h_{i} / h_{1}$ em função do número de nós. (Autoria própria)

\begin{tabular}{cc}
\hline Número de nós & $h_{i} / h_{1}$ \\
\hline 519774 & 1,425468 \\
\hline 593813 & 1,363575 \\
\hline 862288 & 1,204144 \\
\hline 1110827 & 1,106658 \\
\hline 1505522 & 1 \\
\hline
\end{tabular}

O método para garantia de convergência da malha através do parâmetro hi consiste na criação de malhas cada vez mais refinadas e a realização da simulação do processo com cada malha e a partir dessas simulações escolher a mesma variável e comparar os valores destas com o fator $h_{i} / h_{1}$ e observar a partir de qual malha não há mais variação no valor da variável, ou seja, o ponto no qual refinar ainda mais a malha não irá causar mudança nos valores da simulação.

A análise da convergência da malha para a tubulação foi realizada através da comparação entre o parâmetro $h_{i} / h_{1}$ e os valores da temperatura máxima do duto. Essa relação é apresentada na Figura 6.

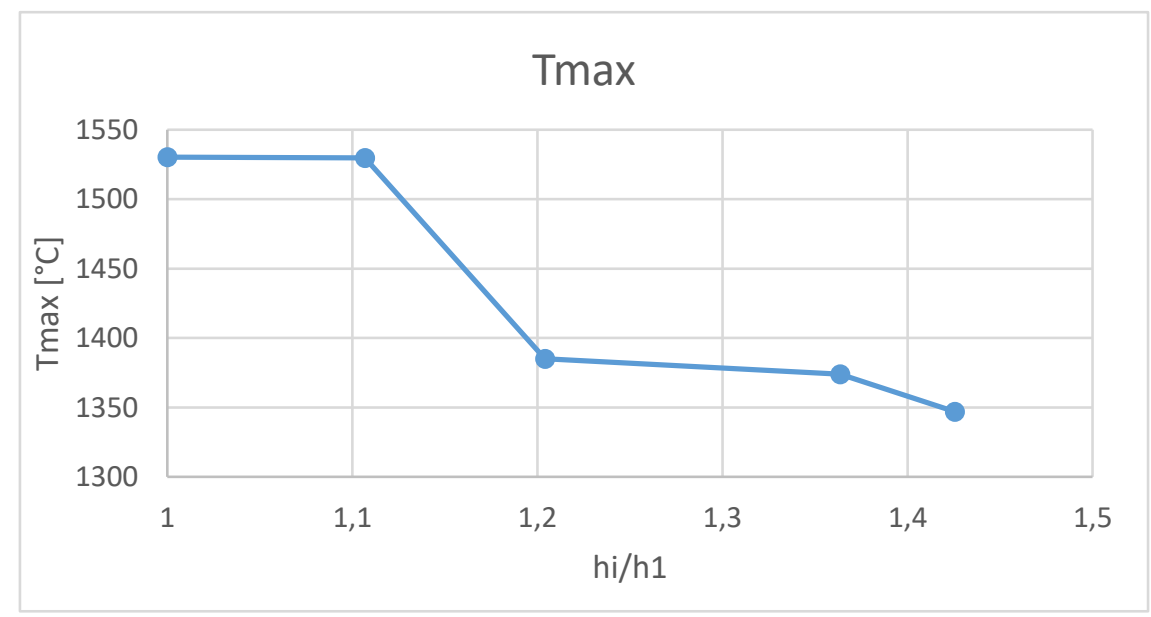

FIGURA 6. Relação de $h_{i} / h_{1}$ e temperatura máxima no duto. (Autoria própria)

É possível visualizar o início de uma convergência dos resultados com o refinamento da malha, porém devido a limitações da máquina na qual será realizada a simulação, a malha cujo parâmetro $h_{i} / h_{1}=1$ foi escolhida.

\subsubsection{Geração da malha para o fluido}

Para a geração da malha do fluido na simulação, foi buscado fazer o ajuste para que o seu parâmetro y+ se aproximasse do valor máximo, $\mathrm{y}+=1$, para ser utilizado no modelo de turbulência $\kappa-\varepsilon$, com isso, o valor da espessura para primeira camada do fluido adjacente às paredes do duto foi obtido como sendo 5,5127 x $10^{-4}$ m. Uma condição de inflation foi aplicada na superfície do fluido na direção normal ao escoamento, de forma 
a criar uma camada com a espessura definida entre a parede do tubo e o fluido, foi definido um número de divisões com um growth rate (taxa de crescimento) de 1,1.

A análise de convergência da malha para o fluido foi feita da mesma maneira que para o duto, porém os valores comparados com o parâmetro $h_{i} / h_{1}$ foram os de temperatura média do fluido na saída do duto. A Figura 7 representa essa relação.

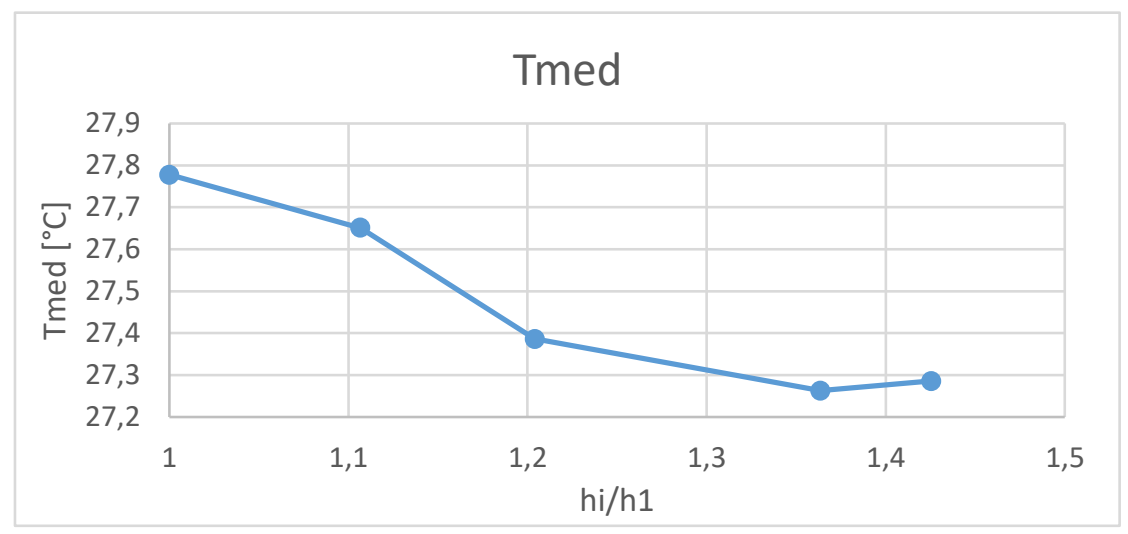

FIGURA 7. Relação de $h_{i} / h_{1}$ e temperatura média do fluido na saída. (Autoria própria)

Não é possível notar uma tendência de convergência da malha, porém como as variações da temperatura com o refinamento da malha apresentam diminuição e para o duto a malha cujo parâmetro $h_{i} / h_{1}$ é igual a 1 já mostrou um início de convergência, essa malha foi adotada também como aceitável para o fluido.

\subsection{Modelagem da fonte de calor para o problema}

A fonte de calor escolhida para a simulação foi a fonte volumétrica hemisférica (Gaussiana), cuja função que a descreve foi apresentada na Equação 6. Para o seu ajuste, é preciso definir o raio característico da distribuição de calor, representado pelo termo “c”, na Equação 6.

Para a determinação desse parâmetro, foi utilizado o método experimental que [6] utiliza, que consiste na realização de soldagens preliminares na parede do duto sem o fluido para analisar algumas características do processo. Os dados utilizados foram retirados de [14], que faz esse tipo de ensaio para dutos de aço AISI 1020 de 3,2mm de espessura de parede, porém utiliza a soldagem com eletrodo revestido. Como o processo de solda ocorre em um material de baixa espessura, a ZAC (Zona Afetada pelo Calor) possui duas medias, a ZAC superior e a inferior, como mostra a Figura 8. O parâmetro "c" foi determinado como sendo aproximadamente $4 \mathrm{~mm}$ que corresponde à metade do comprimento da ZAC superior para um processo de soldagem com uma condição de energia similar à utilizada na simulação, processo EANA05 apresentado em [14].

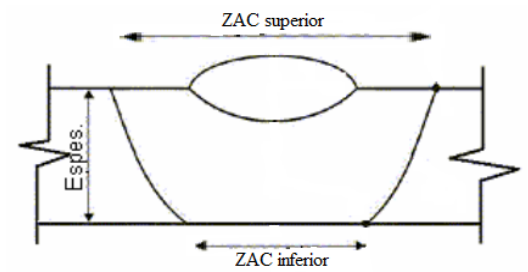

FIGURA 8. Representação da ZAC do processo de soldagem em material fino. (Adaptado de 6)

As condições de soldagem utilizadas na simulação estão apresentadas na Tabela 2.

TABELA 2. Parâmetros de soldagem utilizados na simulação. (Autoria própria)

\begin{tabular}{cccc}
\hline Eficiência do processo & Tensão do $\operatorname{arco}(V)$ & Corrente utilizada $(A)$ & $\begin{array}{c}\text { Velocidade de } \\
\text { soldagem }(\mathrm{mm} / \mathrm{s})\end{array}$ \\
\hline 0,75 & 10 & 155 & 2 \\
\hline
\end{tabular}


A fonte analítica de calor volumétrica hemisférica foi inserida na simulação através de uma User Defined Fucntion (UDF), que consiste em um código em linguagem de programação C, que utiliza funções macro próprias do software e que após ser criado é inserido no solver do ANSYS Fluent®.

\subsection{Propriedades termofísicas do material}

O material utilizado no duto foi o aço AISI 1020, um aço de baixo teor de carbono. Para a determinação das propriedades termofísicas do material que variam em função da temperatura, foi utilizado um recurso próprio do ANSYS Fluent, que permite que as características do material que é simulado sejam definidas através de funções polinomiais cuja variável independente pode ser a temperatura, esse recurso, polynomial fit, é acessado na própria aba de definição do material.

As funções polinomiais que definem as propriedades de calor específico e condutividade térmica, foram definidas através de uma interpolação polinomial feita através do software Matlab, com base nos dados apresentados na Tabela 3, para o calor específico (C) foi gerado um polinômio de quarta ordem, e para a condutividade térmica $(\mathrm{K})$, um de sétima ordem.

TABELA 3. Propriedades termofísicas do aço de baixo carbono (Adaptado de [7]).

\begin{tabular}{ccccccccccccc}
\hline $\mathrm{T}\left({ }^{\circ} \mathrm{C}\right)$ & 0 & 200 & 400 & 600 & 800 & 1000 & 1200 & 1400 & 1600 & 1800 & 2000 \\
\hline $\mathrm{C}\left(\mathrm{J} \cdot \mathrm{kg}^{-1} \cdot{ }^{\circ} \mathrm{C}^{-1}\right)$ & 500 & 550 & 600 & 800 & 950 & 950 & 950 & 950 & 950 & 950 & 950 \\
\hline $\mathrm{K}\left(\mathrm{W} \cdot \mathrm{m}^{-1} \cdot{ }^{\circ} \mathrm{C}^{-1}\right)$ & 52 & 50 & 43 & 37 & 26 & 28 & 30 & 33 & 120 & 120 & 120 \\
\hline
\end{tabular}

\subsection{Condições de contorno da simulação}

Para simular o fluido que escoa dentro da tubulação, foi utilizada a água, pois a realização do experimento prático da simulação apresentada neste trabalho é objetivada em projeto futuro. Na simulação utilizou-se o próprio material padrão presente no ANSYS para a água, Water-liquid, cujas propriedades estão presentes na Tabela 4.

TABELA 4. Dados da água na simulação. (Autoria própria)

\begin{tabular}{cccc}
\hline $\begin{array}{c}\text { Densidade } \\
\left(\mathrm{kg} \cdot \mathrm{m}^{-3}\right)\end{array}$ & $\begin{array}{c}\text { Calor específico } \\
\left(\mathrm{J} . \mathrm{K}^{-1} \cdot{ }^{\circ} \mathrm{C}^{-1}\right)\end{array}$ & $\begin{array}{c}\text { Condutividade térmica } \\
\left(\mathrm{W} \cdot \mathrm{m}^{-1} \cdot{ }^{\circ} \mathrm{C}^{-1}\right)\end{array}$ & $\begin{array}{c}\text { Viscosidade } \\
\left(\mathrm{kg} \cdot \mathrm{m}^{-1} \cdot \mathrm{s}^{-1}\right)\end{array}$ \\
\hline 998,2 & 4182 & 0,6 & 0,001003 \\
\hline
\end{tabular}

O escoamento do fluido foi definido a partir da vazão mássica que entra na tubulação, foi definida uma vazão mássica de $0,5(\mathrm{~kg} . \mathrm{s}-1)$ na direção normal à direção do escoamento, foi considerada uma saída sem diferença de pressão. O modelo de turbulência escolhido para a simulação foi o $\kappa-\varepsilon$, que por ser um modelo de apenas duas equações, gera uma economia de recursos computacionais.. 


\section{RESULTADOS E DISCUSSÕES}

Os resultados gráficos da simulação juntamente com todos os dados a respeito dos campos transientes de temperatura, ciclo térmico e análise de zonas de fusão e termicamente afetadas foram obtidos através do plugin CFD-post processor do próprio software ANSYS®.

\subsection{Campos transientes de temperatura}

A formação dos campos transientes de temperatura na parede superior do tubo pode ser vista com relação ao tempo do processo de soldagem na Figura 9. Nela está representado o procedimento em cinco diferentes estágios, em três deles a fonte analítica de calor ainda está iniciando a entrada no material e nas duas últimas, toda a fonte já se encontra sobre o material.

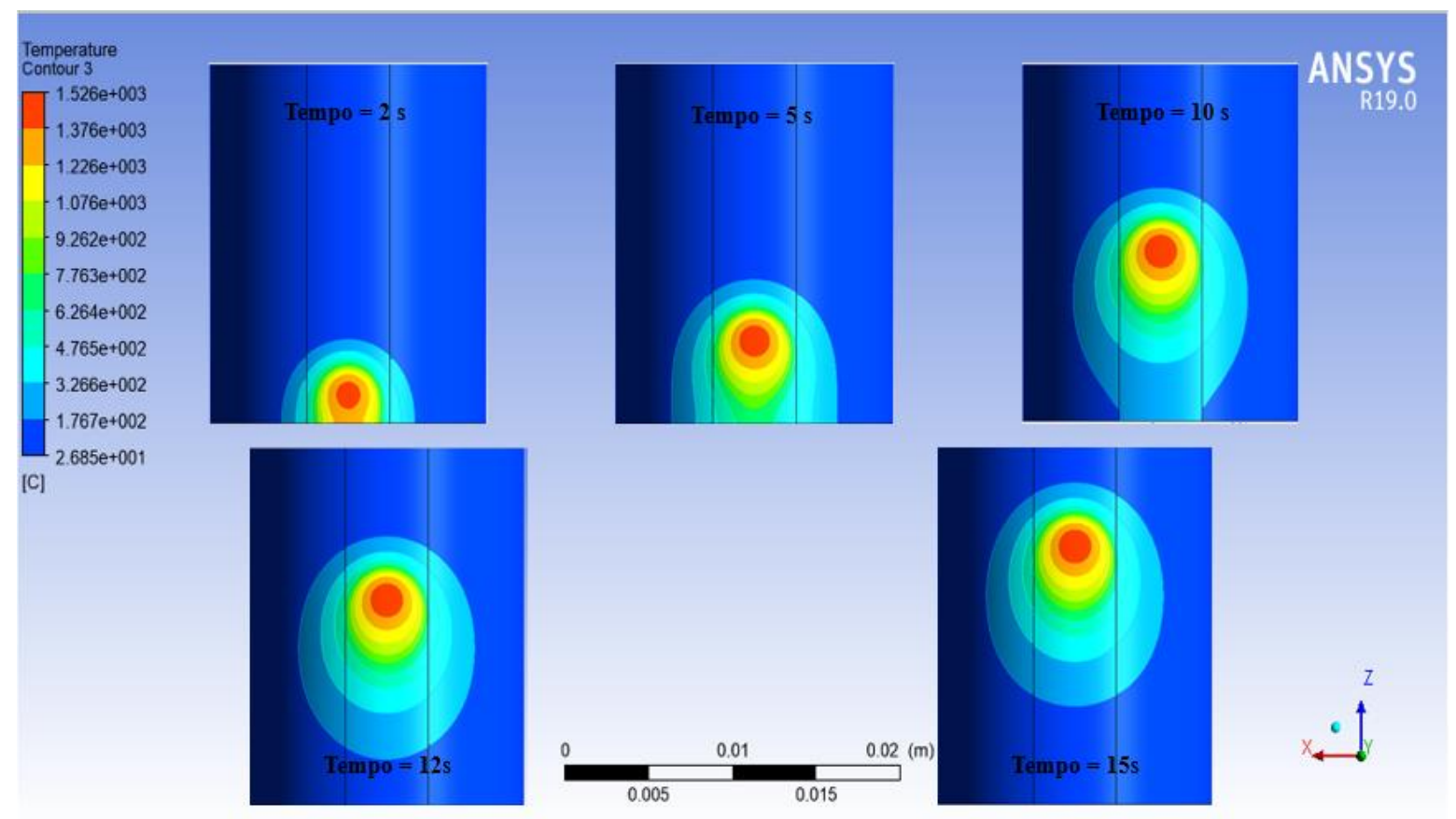

FIGURA 1. Formação dos campos transientes de temperatura com relação ao tempo. (Autoria própria)

Na Figura 9 é possível notar a formação das isotermas em formato hemisférico, característica da fonte de calor utilizada. As partes compreendidas pela isoterma vermelha, representam as áreas fundidas, pois sua temperatura supera a de fusão do material, $1500^{\circ} \mathrm{C}$ [7]. Um fato a ser notado sobre este resultado é o resfriamento forçado da parte do material onde a fonte de calor já passou, logo após a sua passagem a temperatura da peça já volta a faixa dos $26^{\circ} \mathrm{C}$, esse efeito é visível na comparação da imagem entre 10 e $15 \mathrm{~s}$.

Como o ajuste da fonte de calor analítica volumétrica hemisférica foi feito através de dados obtidos de um processo de soldagem diferente com níveis de energia similares, os valores obtidos para a caracterização dos campos transientes de temperatura podem apresentar erros. Outra fonte de erros é a aproximação feita para os comportamentos das variáveis termofísicas do material e a consideração de densidade constante.

\subsection{Análise da Zona Fundida (ZF) e Zona Afetada pelo Calor (ZAC)}

O estudo das zonas fundida e afetada pelo calor, foi feito através da análise dos contornos de temperatura em um plano XY, localizado a uma distância de $10 \mathrm{~mm}$ da origem no momento em que o centro da fonte de calor está sobre esta posição, ou seja, no tempo $(5 \mathrm{~s})$ onde o local possui uma maior quantidade de energia térmica sobre ele. A Figura 8, traz a representação desse plano, os termos "a" e "b" representam a penetração e largura da zona fundida, respectivamente.

Para a medição das zonas afetadas pelo calor, superior e inferior, foi considerada toda a região com uma temperatura superior à de austenitização do material, que é de aproximadamente $800^{\circ} \mathrm{C}$ [7]. Na Figura 10 , a 
zona afetada pelo calor superior é indicada pela representação "ZAC-sup" e a inferior está indicada por "ZACinf".

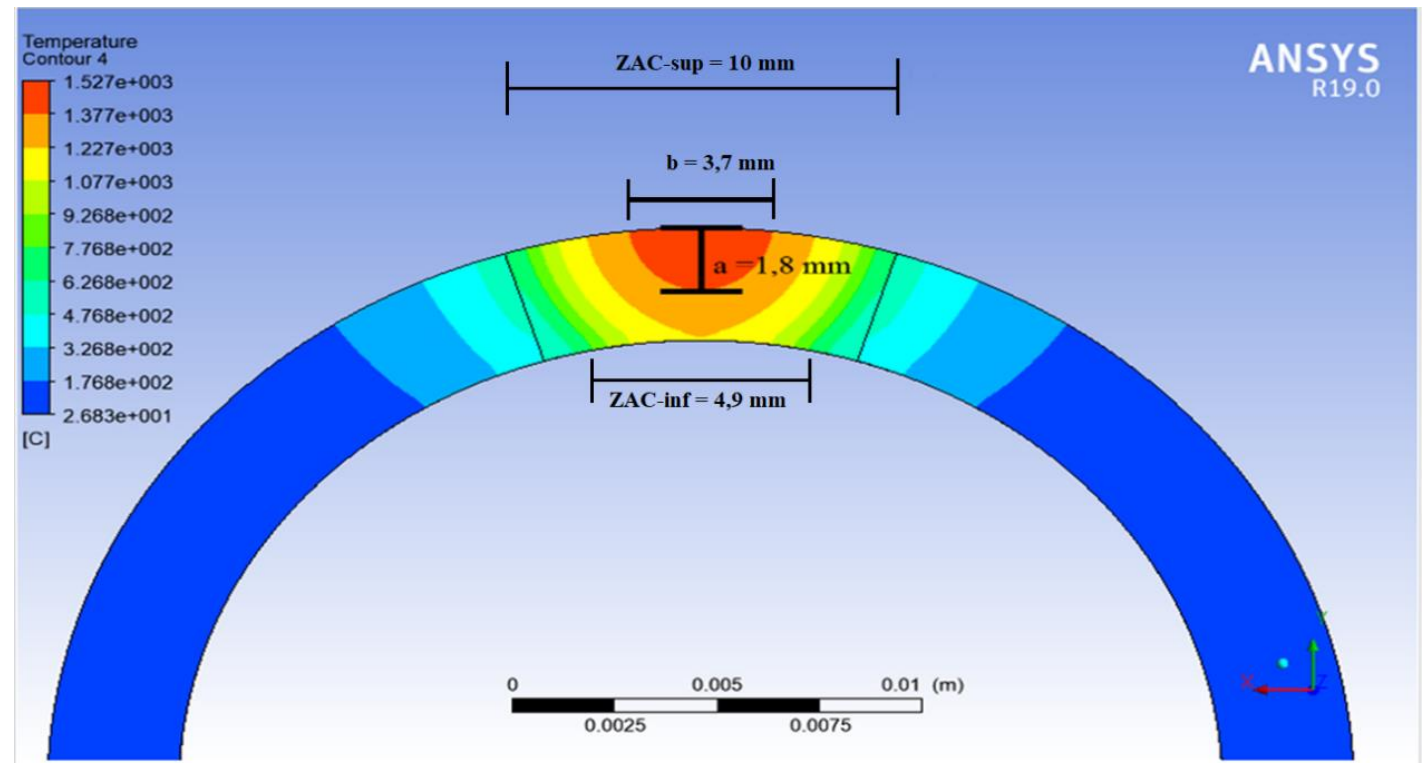

FIGURA 10. Zonas de fusão e afetada pelo calor (Autoria própria)

De acordo com a Figura 10, não houve a perfuração da parede do tubo durante o processo de soldagem, uma vez que o material só fundiu até uma profundidade de $1,8 \mathrm{~mm}$, o que mostra que para os parâmetros de soldagem escolhidos, é possível, segundo a simulação, a realização da soldagem em operação no duto. Durante a realização das simulações, os parâmetros de soldagem foram sendo mudados para garantir a ocorrência da soldagem no tubo, e esta só ocorreu com o uso de uma corrente relativamente alta para o processo de soldagem TIG, 155 A. Quando a simulação foi realizada sem a água no interior do tubo com valores mais baixos de corrente era possível obter a fusão de parte do material.

Devido ao número de contornos escolhidos na imagem para uma melhor visualização, parte do gradiente de temperaturas ficou omitido, pois após a isoterma vermelha, que apresenta uma temperatura quase constante, cada contorno possui uma grande variação de temperatura na direção negativa de y.

Da mesma forma como na determinação dos campos transientes de temperatura, as fontes de erros para os dados obtidos podem estar no ajuste da fonte de calor e nas propriedades do material. Como os valores do comprimento da ZAC utilizado na fonte hemisférica é referente a um estudo preliminar onde não há fluido escoando no interior do duto, não se faz lógica a comparação de tal dado experimental com o obtido através da simulação.

\subsection{Efeito do processo de soldagem no fluido}

A Figura 11 mostra o efeito do processo de soldagem no fluido que escoa dentro da tubulação no mesmo tempo (5s) em localizações diferentes. A troca de calor entre o duto e o fluido mostra o resfriamento forçado que a tubulação sofre devido ao efeito do escoamento em seu interior. 


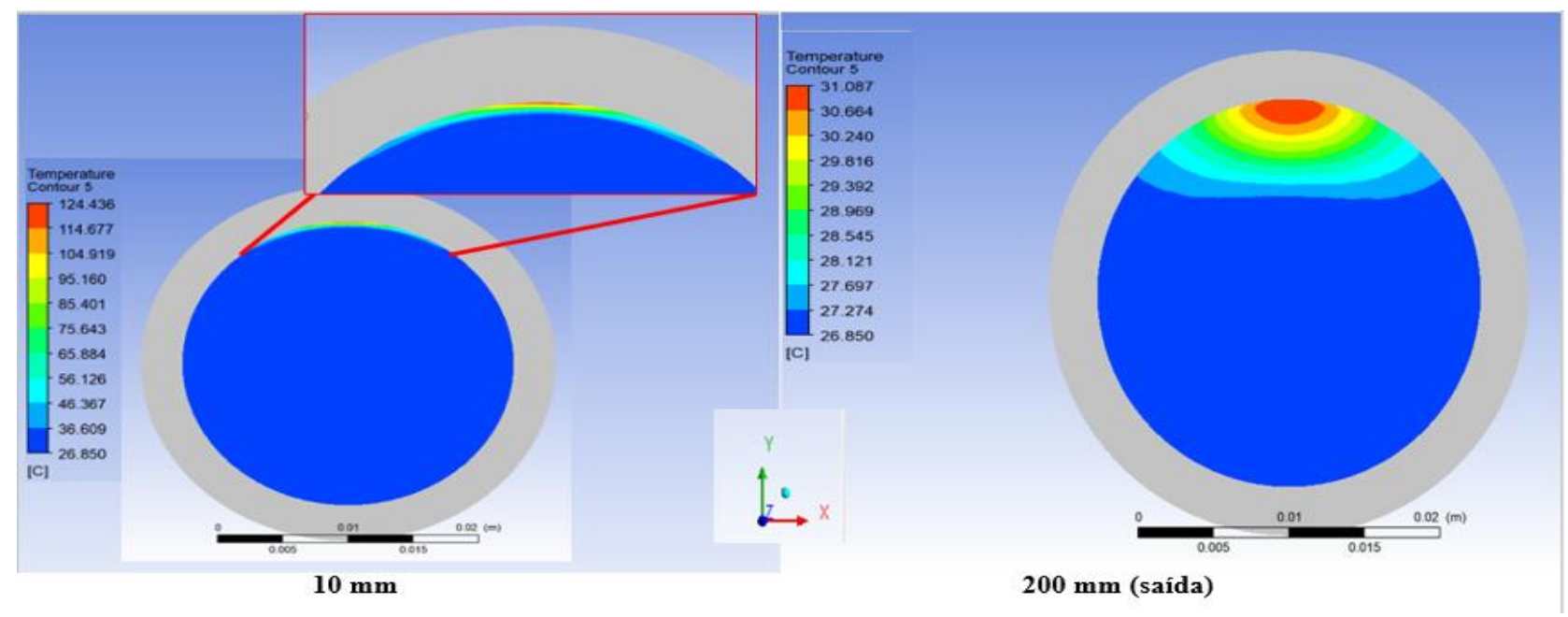

FIGURA 11. Efeitos do processo de soldagem no fluido (Autoria própria).

O comportamento do fluido dentro da tubulação evidencia a severidade das trocas de calor que ocorrem nesse processo, uma vez que a água varia, em poucos segundos, de temperaturas acima da de fusão até a temperatura ambiente. A partir da Figura 11, também é possível notar que a depender da velocidade do fluido escoando dentro do tubo a troca de calor com o material soldado será mais influenciada, uma vez que o tempo de contato de parte do fluido com a região onde a fonte de calor se encontra será maior.

Uma possível fonte de erro quanto aos dados obtidos para o fluido é a mudança de fase da água, pois a temperatura máxima alcançada no escoamento ultrapassa a de evaporação. Outra simplificação adotada no trabalho que pode gerar falta de precisão da simulação é a consideração que as propriedades termofísicas da água são constantes.

\subsection{Ciclo térmico no material}

O ciclo térmico ao qual o material está sujeito foi determinado no ponto de interesse para a determinação da existência de perfuração na parede do duto. O ponto analisado foi localizado na face interna da tubulação na parte superior a uma distância de $10 \mathrm{~mm}$ da origem, para garantir que a fonte de calor já estava totalmente desenvolvida no material. A Figura 12 indica a variação da temperatura deste ponto em função do tempo.

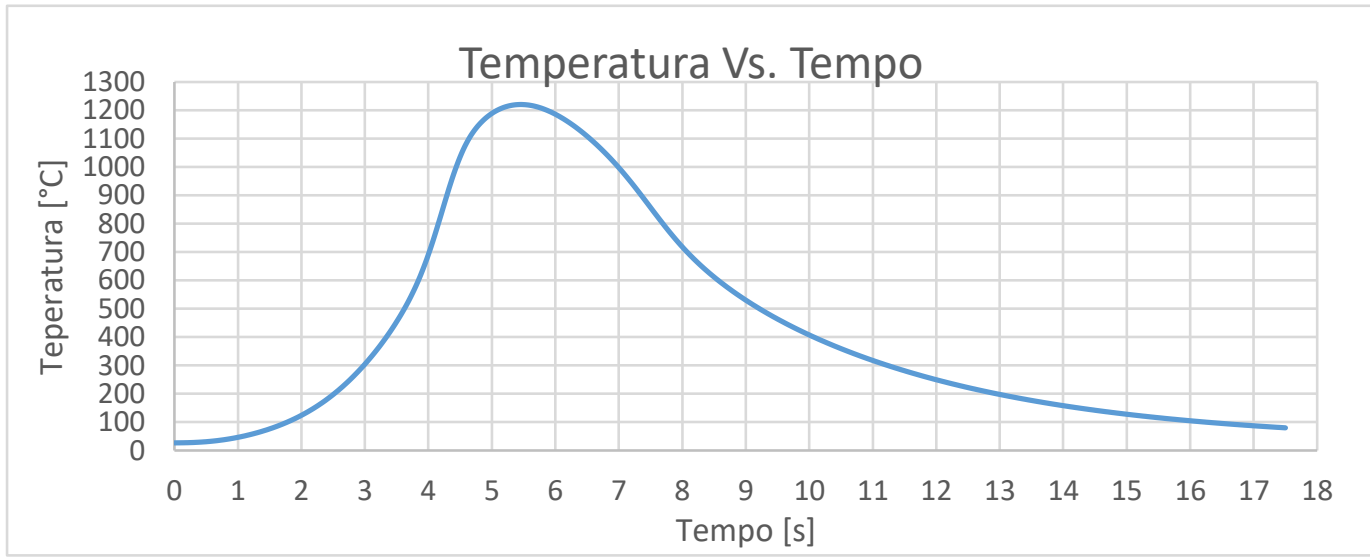

FIGURA 12. Ciclo térmico para um ponto da tubulação. (Autoria própria)

A partir da Figura 12 é possível perceber, de maneira mais quantitativa, a que ciclo térmico o material está sujeito, no ponto analisado a temperatura, em $5 \mathrm{~s}$, sai de $1200^{\circ} \mathrm{C}$ para $400^{\circ} \mathrm{C}$. Mudanças de temperaturas tão bruscas como esta submetem o material à uma alta tensão residual, além de uma grande mudança em sua microestrutura uma vez que ele sai do campo austenítico muito rapidamente. 
A análise do resfriamento a que o tubo está sujeito permite a constatação que a realização desse processo em ligas de aço com maior teor de carbono pode gerar algumas dificuldades adicionais, pois por terem mais carbono em sua constituição, quando passar pelo rápido resfriamento formará uma maior quantidade de martensita em comparação com o aço AISI 1020, o que pode fragilizar ainda mais o material.

\section{CONCLUSÃO}

O estudo dos efeitos do processo de soldagem em operação para um duto de aço baixo carbono com água escoando em seu interior, obteve êxito em sua determinação através da simulação computacional, porém, devido ao tempo de desenvolvimento deste trabalho, não foi possível a realização de ensaios experimentais que pudessem validar a simulação e verificar a sua precisão. A falta de trabalhos acessíveis na área de soldagem em operação que tragam em seu conteúdo os dados para uma análise térmica do processo como realizado na simulação também impossibilitou a comparação dos resultados obtidos numericamente com os experimentais.

Com base na pesquisa que levou a realização deste artigo, os trabalhos que abordam a simulação de soldagem, geralmente, trazem simulações de processos de soldagem em chapas, sem levar em consideração o efeito de algum fluido escoando sobre a peça. A contribuição deste artigo está justamente em simular um processo onde a soldagem acontece em um elemento com fluido escoando em seu interior, isto é, a soldagem em carga, um processo altamente utilizado na indústria.

As simplificações do modelo, como já discutido nos resultados e discussões, podem ter ocasionado incertezas. $\mathrm{O}$ ajuste da fonte analítica de calor ter sido feito utilizando dados de um processo com algumas diferenças do proposto pode ter causado erros que poderiam ter sido evitados apenas com a realização de uma macrografia sobre um duto que passou pelo processe de soldagem nas condições propostas para a simulação, porém a falta de recursos e tempo de desenvolvimento acabou por limitar o trabalho6. Agradecimentos

\section{REFERÊNCIAS}

[1] OLIVEIRA, J. F. M; Análise e reparo em dutos corroídos. Um estudo de caso para reparo por dupla calha. 2016. 128p. Monografia (Especialização em Engenharia de Dutos) - Pontifícia Universidade Católica do Rio de Janeiro, Rio de Janeiro, 2016.

[2] ARAÚJO, D. B. Estudo de distorções em soldagem com uso de técnica numérica e de otimização. 2012. 212p. Tese (Doutorado em Engenharia Mecânica) - Universidade Federal de Uberlândia, Uberlândia 2012.

[3] MELO, R. L. F; Obtenção numérica e experimental do campo de temperatura na soldagem TIG do aço AISI 304. 2016. 85p. Projeto de conclusão de curso (Graduação em Engenharia Mecânica) - Universidade Federal Rural do Semi-Árido, Mossoró, 2016.

[4] BEZERRA, A. C. Simulação numérica da soldagem com aplicação à caracterização do comportamento dinâmico de estruturas soldadas. 2006. 232p. Tese (Doutorado em Engenharia Mecânica) - Universidade Federal de Uberlândia, Uberlândia, 2006.

[5] MARQUES, P. V. et al. Soldagem fundamentos e tecnologias. 3 ed. Belo horizonte: editora UFMG, 2011. [6] MASCARENHAS, L. A. B. Estudo da aplicação do processo TIG alimentado para soldagem em operação. 2005. 106p. Dissertação (Mestrado em Engenharia Mecânica) - Universidade Federal de santa Catarina, Florianópolis, 2005.

[7] SOUZA, C. F. M. Análise numérica e experimental de tensões residuais em juntas soldadas de aço de baixo carbono. 2016. 130p. Dissertação (Mestrado em Engenharia de Materiais e de Processos Químicos e Metalúrgicos) - Pontifícia Universidade Católica do Rio de Janeiro, Rio de Janeiro, 2016.

[8] PARRE, M. D. Heat and fluid flow modeling in twin-wire welding. 2011. 65p. Dissertação (Mestrado em Engenharia Mecânica) - Indian Institute of Technology Hyderabad, Índia, 2011.

[9] INCROPERA, F. P. et al. Fundamentos de transferência de calor e massa. 6 ed. Rio de Janeiro: LTC,2018. [10] ANSYS. ANSYS Fluent theory guide. [s. L]: Ansys, 2016.

[11] FERRO, Luís Morão Cabral. Estudo experimental numérico e experimental do escoamento numa turbina hidráulica axial. 2009. 297 f. Tese (Doutorado) - Curso de Engenharia Mecânica, Universidade Técnica de Lisboa, Lisboa, 2009.

[12] PÉREZ, G. E. G. Estabelecimento de critérios para evitar a perfuração na soldagem de tubulações em operação de pequena espessura. 2005. 102p. Dissertação (Mestrado em Engenharia Mecânica) - Universidade Federal de Santa Catarina, Florianópolis, 2005. 